\title{
نوذج مقترح لتنمية التفكير الاستراتيجي لدى القادة بالجامعات الليبية في ضوء بعض النماذج والنطبيقات الأجنبية
}

$$
\begin{aligned}
& \text { د. فتحي عيســـى فـــــ } \\
& \text { جامعة عمر المختار -البيضاء }
\end{aligned}
$$

د.كريمة المبروك علي الرقيعي

جامعة عمر المختار -درنة

ملخص البحث: هدف البحث الحالي إلى إقتراح تصور لتنمية التفكير الاستراتيجي لدى

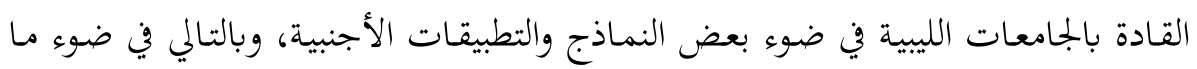
سبق سيتم تحديد مشكلة البحث الحالي في السؤال الرئيس التالي:

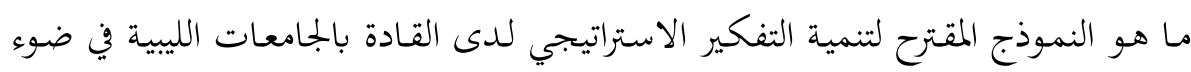
بعض النماذج والتطبيقات الأجنبية ؟ ويتفرع من السؤال الرئيس الأسئلة الفرعية التالية:

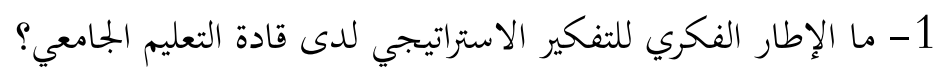

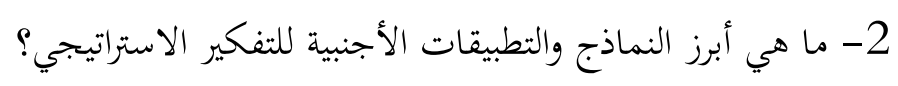

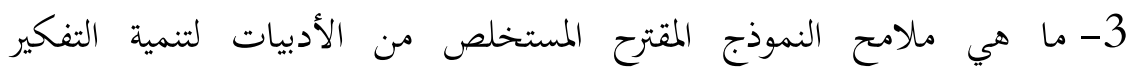
الاستراتيجي لدى القادة بالجامعات الليبية في ضوء بعض النماذج الأجنبية؟ ملهو واعتمد البحث على المنهج الوصفي لتحقيق أهدافه، وتم التوصل لعدد من النتائج وهي:

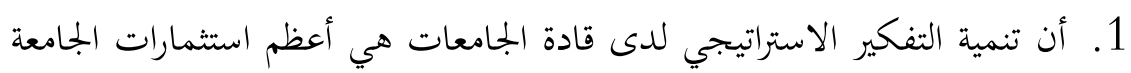

$$
\text { لراس مالها الفكري والقادر على تحقيق الميزة التنافسية. }
$$

2. ضرورة نشر ثقافة التفكير الاستراتيجي داخل البيئات الجامعية بداية من رؤساء

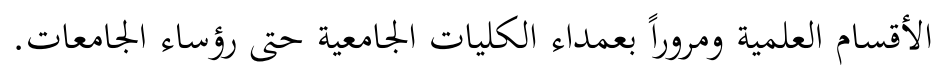

$$
\text { الكلمات المفتاحية: النفكير الاستراتيجي - القادة - النعليم الجامعي }
$$




\section{Abstract}

The objective of the current research is to propose a vision for the development of strategic thinking among the leaders of Libyan universities in the light of some foreign models and applications. Therefore, in light of the above, the current research problem is determined in the following main question:

-What is the proposed model for the development of strategic thinking for leaders of Libyan universities in light of some foreign models and applications?

The following sub-questions stem from the main question:

What is the intellectual framework for strategic thinking and leaders of Education university?

2-What are the most prominent foreign models and applications of strategic thinking?

3-What are the features of the proposed model derived from the literature for the development of strategic thinking for the leaders of the Libyan universities in the light of some foreign models?

The research was based on the descriptive approach to achieving the goals that were identified. The research reached for results:

1-The development of strategic thinking among university leaders is the university's greatest investment for its intellectual capital and capable of achieving competitive advantage.

2- The need to spread the culture of strategic thinking within the university environments, from the heads of the scientific departments and through of the university colleges to the presidents of universities.

Keywords: Strategic Thinking - Leaders - University Education

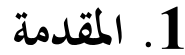

تُعد الجامعة من المؤسسات التعليمية التي تحتل قمة النظام التعليمي وتلعب دوراً كبيراً في رفد المجتمع بالكفاءات والمهارات القادرة على التكيف والمرونة وبناء قوى عاملة مؤهلة وخلاقة تستطيع أن تتكيف مع التكنولوجيا الجديدة، كما تلعب الجامعة دوراً رئيسياً في صناعة المعرفة التي تخدم التنمية الشاملة من مختلف الأوجه الاقتصادية والثقافية والسياسية. 


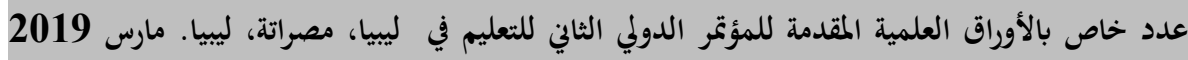

وقد تزايد الاهتمام في الآونة الأخيرة لدى معظم الدول بتطوير التعليم الجامعي بهدف

الإرتقاء بمستوى آدائه في ظل حدة التغيرات والتحديات التي يفرضها بجتمع المعرفة وما يصاحبه من تداعيات مختلفة بصورة مستمرة، وذلك من خلال التركيز على الرؤى الاستراتيجية للقادة الجامعيين وأساليب التطوير والتي يأتي في مقدمتها التفكير الاستراتيجي. وإذ كانت استراتيجية الجامعة كتم بمجموعة الخطط والبرامج التي يتم إعدادها لتطوير أسلوب العمل والذي يسهم في تحقيق إنجاز فعال للأهداف في ضوء سياستها المحددة، فأن صياغتها تتم عن طريق مشاركة الأفراد الذين يمتلكون القدرة على التفكير السليم والابتكار، الابداع، والمعرفة العلمية بالعمليات التي تتم في الجامعة (ضحاوي: 2011، ص 83). وعلى الرغم من ورود مصطلح التفكير الاستراتيجي على استحياء ضمن الإدارة التربوية وخاصة الإدارة الجامعية ألا أن هذا المصطلح اتسعت دائرة استخدامه في فهايات القرن العشرين وذلك ضمن الإدارة الاستراتيجية والتخطيط الاستراتيجي، وأن استخدام التفكير الاستراتيجي من قبل قادة الجامعات له تأثير حتمي على تحدي التوجهات الاستراتيجية للجامعات، والذي يجمع بين المعرفة الاستراتيجية والسياق والوعي التنظيمي لتشكيل محددات الأعمال وصياغتها وتعريفها من أجل اكتساب ميزة تنافسية على المدى القصير والمتوسط وطويل الأجل(Campbell: 2011, p22). أن القادة في الجامعات يفكرون أولاً تفكيراً استراتيجيا في تغيير الواقع الحالي، باستخدام أدوات ومفاهيم التخطيط الاستراتيجي وصياغة استراتيجيات التطوير لتصبح في حيز التنفيذ على أن تحقق هذه الاستراتيجيات ميزة تنافسية للجامعات باستحضار كل ماهو جديد ومختلف تماماً عن الجامعات الأخرى، وفي إطار هذا توصلت إحدى الدراسات العلمية بجامعة فلوريدا أطلانتك في الولايات المتحدة الامريكية، إلى أن استخدام بروتوكول التفكير الاستراتيجي يلائم منظمات التعليم العالي وذلك لتأسيس بيئة تعلم يمكنها تنفيذ

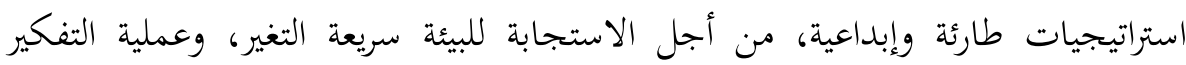
الاستراتيجي لمعظم قضايا القسم الاكاديمي والكلية تكون فعالة في تعديل الاتحاهات والقيم 
عدد خاص بالأوراق العلمية المقدمة للمؤتم الدولي الثاني للتعليم في ليبيا، مصراتة، ليبيا. مارس 2019

والمعتقدات للمشاركين، وبالتالي فإن إدراج عناصر التفكير الاستراتيجي بمثل نموذج التغيير الفعال لمؤسسات التعليم العالي(Robinson: 2012,p17). وفي ضوء ما سبق، نجد أن قادة التعليم الجامعي في ليبيا لابد لهم من تنمية التفكير الاستراتيجي، والذي سيزودهم بالآليات المناسبة لتغيير الواقع الحالي وتحقيق الميزة التنافسية لجامعاهم، وذلك من خلال استخدام أدوات ومفاهيم التخطيط الاستراتيجي وصياغة الاستراتيجيات لتطوير التعليم وجودته لدخول أبواب المستقبل. 1.1

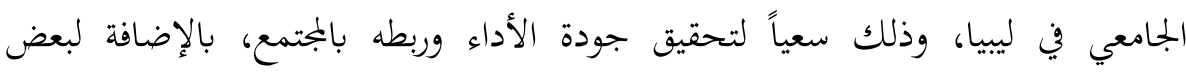
المحاولات البسيطة لتطوير قدرات ومهارات القادة بالجامعات الليبية، وخاصة ما يتعلق بالخطط الاستراتيجية من خلال التفكير الاستراتيجي الذي يحقق الميزة التنافسية لهذه الجامعات، إلا أن هناك العديد من العوامل التي ساهمت في تغليب الطابع التقليدي على أسلوب التفكير الاستراتيجي للقادة في الجامعات الليبية وذلك على النحو التالي: أ- تفتقد الجامعات الليبية للاستقلالية والحرية الأكاديمية، مع زيادة حجم الرقابة المركزية على التعليم الجامعي في ليبيا، فلا تستطيع اتخاذ القرارات النهائية في كثير من الأمور الجوهرية للجامعة، وتكتفي بالتوصية فقط بمثل هذه القرارات حيث تتخذها عنها وزارة

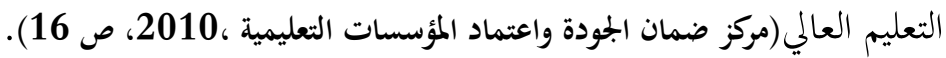
ب-أوضح تقرير المنظمة الليبية للسياسات والاستراتيجيات إلى أن هناك العديد من الصعوبات والمعوقات التي تواجه التعليم الجامعي في ليبيا ومنها ( المنظمة الليبية للسياسات

$$
\text { والاستراتيجات،2017، ص ص 10-11) : }
$$

(1) تفشي البيروقراطية والترهل الإداري وضعف الأداء في العناصر الإدارية والمالية مع صع صعات عدم القدرة على تطبيق اللوائح الأكاديمية. 
عدد خاص بالأوراق العلمية المقدمة للمؤتمر الدولي الثاني للتعليم في ليبيا، مصراتة، ليبيا. مارس 2019

(2) الافتقار إلى التخطيط التربوي في مؤسسات التعليم الجامعي بسبب ضعف تأهيل وتطوير القيادات الجامعية مما يجعلهم غير قادرين على التخطيط الاستراتيجي للمستقبل وبالتالي فقدان الميزة التنافسية مع نظيراتما من الجامعات العالمية. (3) قصور الوعي لدى وزارة التعليم العالي وكذلك الجامعات الليبية بجدوي برامج

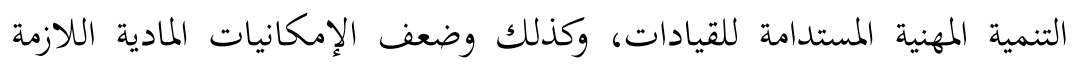
لتحقيق هذه البرامج التدريبية والتنموية بما يتماشى مع المتغيرات والتطورات

$$
\text { العصرية (الرقيعي، 2016، ص ص 10 10-13 ). }
$$

وفي ضوء ما سبق يمكن بلورة مشكلة البحث الحالي في السؤال الرئيس التالي: ما هو النموذج المقترح لتنمية التفكير الاستراتيجي لدى القادة بالجامعات الليبية في

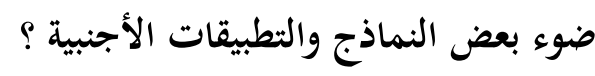
ويتفرع من السؤال الرئيس الأسئة الفرعية التالية:

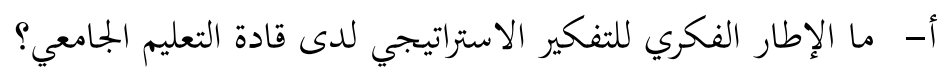

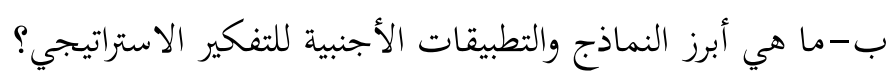

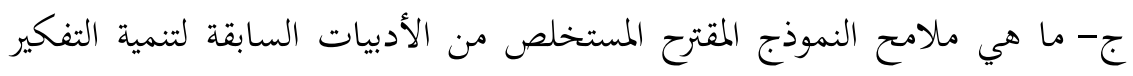
الاستراتيجي لدى القادة بالجامعات الليبية في ضوء بعض النماذج والتطبيقات

الأجنبية وبما يواكب السياق الثقافي للمجتمع الليبي؟ لإنيات

$$
\text { 2,1 أهمية البحث : تنبع أهمية البحث الحالي مما يلي: }
$$

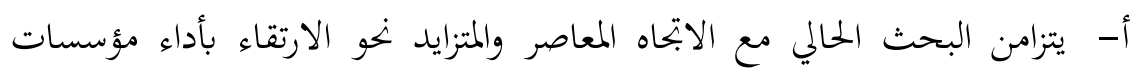
التعليم الجامعي عن طريق تطبيق معايير الجودة والتي يأتي في مقدمتها معيار التفكير الاستراتيجي الذي يساهم في تطوير أداء المؤسسة الجامعية ويحقق لها الميزة التنافسية أمام نظيراتها. 
ب-إن تناول التفكير الاستراتيجي وتنميته لدى قادة الجامعات الليبية لما يجد الاهتمام الكافي بالدراسة والبحث من قبل الدراسات السابقة وخاصة المحلية منها.

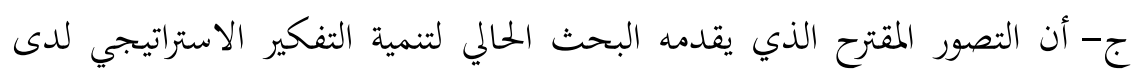

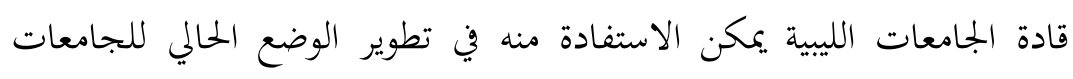

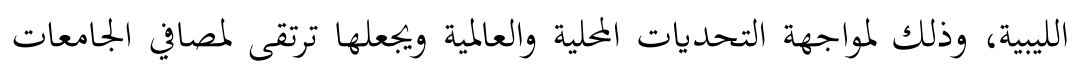

\section{العالمية.}

3,1 أهداف البحث : ويهدف البحث الحاالي لتحقيق ما يلي:

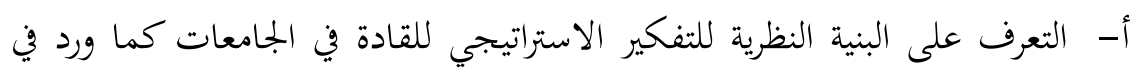

$$
\text { الادبيات السابقة. }
$$

ب-التعرف على النماذج والتطبيقات الأجنبية السباقة في تطبيق التفكير الاستراتيجي وذلك بغرض الاستفادة منها في وضع النموذج المقترح، والذي سيساهم في تنمية التفكير الاستراتيجي لدى قادة الجامعات الليبية لتحقيق معدلات أعلى في الأداء

$$
\text { وبأكثر كفاءة وجدارة. }
$$

1. 4 مصطلحات البحث: وأقتصر البحث الحالي على مصطلح التفكير الاستراتيجي وبالتالي قام (جارات Garratt) بتعريف التفكير الاستراتيجي بأنه هو " العملية التي تمكن

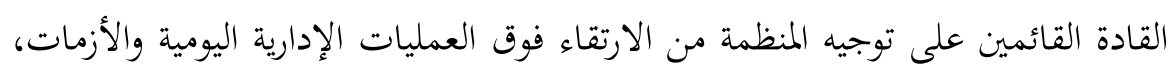

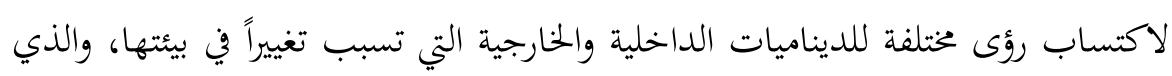
يعطي ابتحاه أكثر فعالية لمنظماهم، وهذه الرؤى موجهة نحو المستقبل وأن يمتلك المفكرون

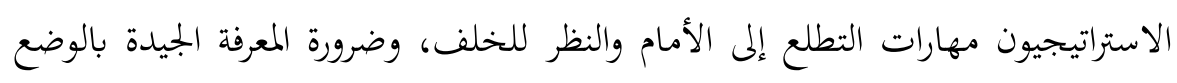

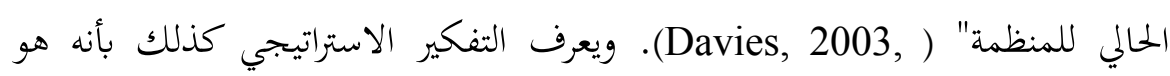
"توليف أو تركيب ينطوي على الحدس والابداع وتتمثل نتائج هذا التفكير في مجمل

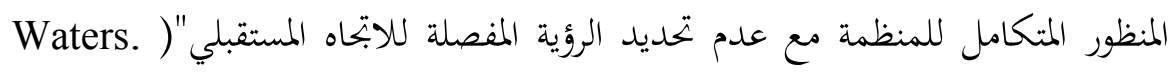


2011. P114)، ويعرف (يونس: 2006، ص 9) التفكير الاستراتيجي أنه هو

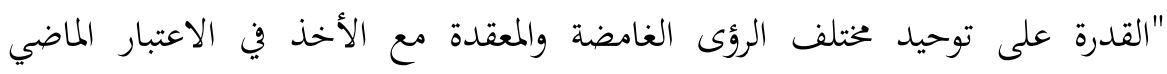

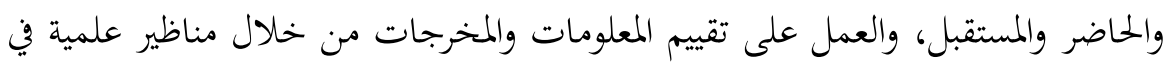

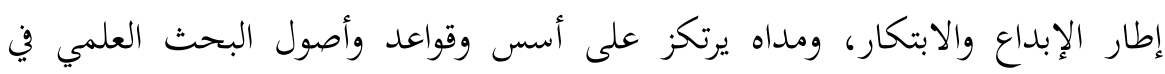

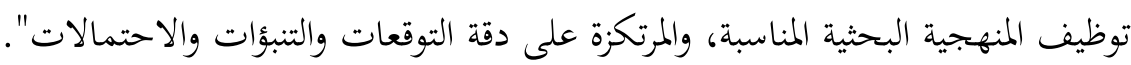

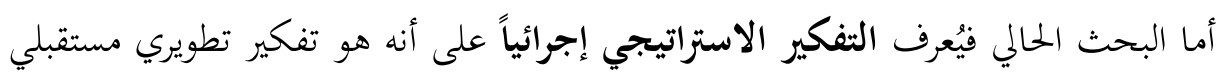

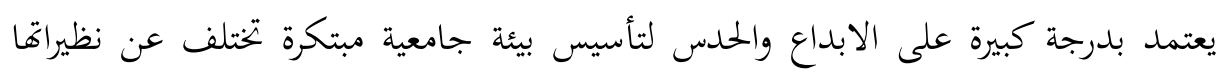

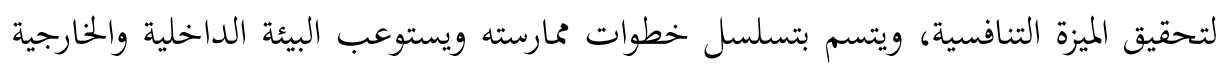

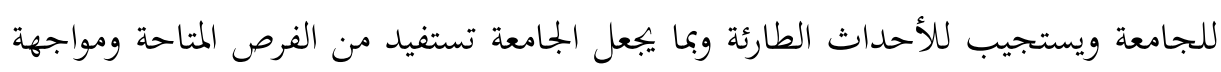

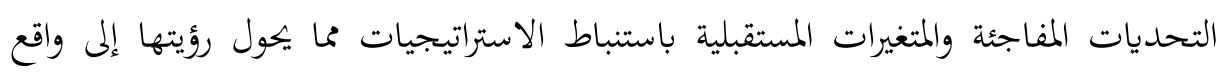
يرفغ كفاءة أدائها.

2. المنهج والإجراءات: يتبع البحث الحالي المنهج الوصفي باعتباره المنهج المناسب

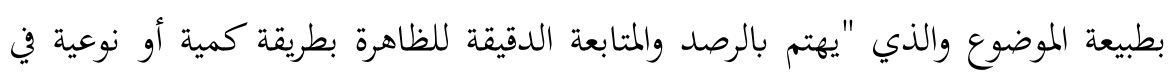

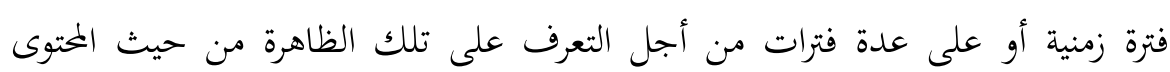

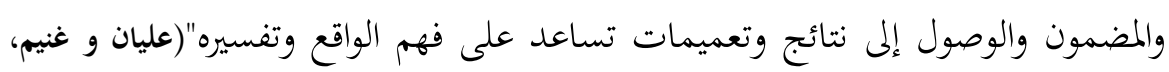
2000، ص 43). ويمر البحث بثلاث خطوات منهجية للإجابة على تساؤلات البحث

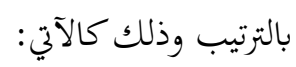
الحطوة الأولى: إطار نظري للقادة الجامعيين وتفكيرهم الاستراتيجي:

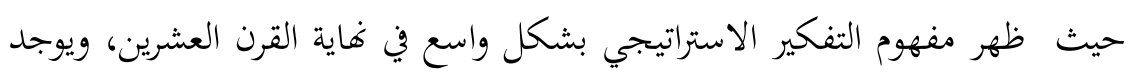

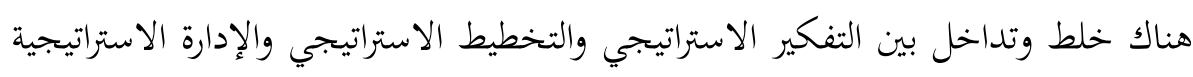

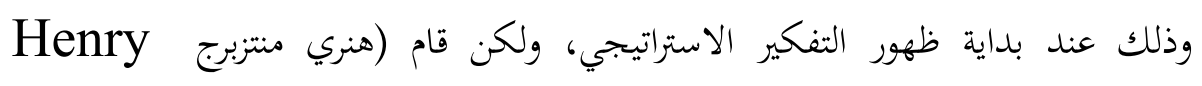

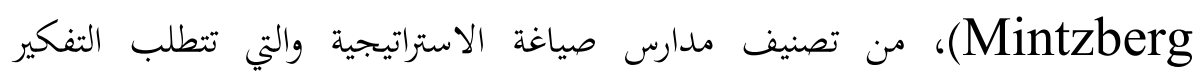




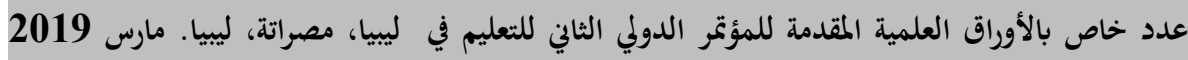

الاستراتيجي والتخطيط الاستراتيجية واللذان يعدان ركيزتان اساسيتان للإدارة الاستراتيجية. ويرى منتزبرج أن التفكير الاستراتيجي يعتمد أكثر على الإبداع والحدس من القدية القيام

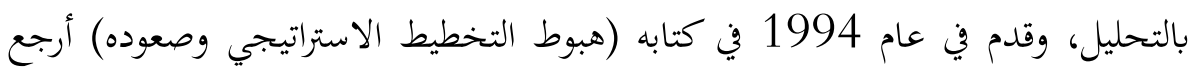
قصور التخطيط الاستراتيجي وأنه ليس هو التفكير الاستراتيجي والذي هو"توليف أو تركيب ينطوي على الحلد والابداع وتتمثل نتائجه فالتفكير في مجمل المنظور المتكامل للمنظمة وعدم تحديد الرؤية المفصلة للاتجاه المستقبلي" (Waters. 2011. P114). ووضع (جارات Garratt)، تعريفاً متميزاً للتفكير الاستراتيجي عرفه بأنه هو " العملية التي تمكن القادة القائمين على توجيه المنظمة من الارتقاء فوق العمليات الإدارية اليومية

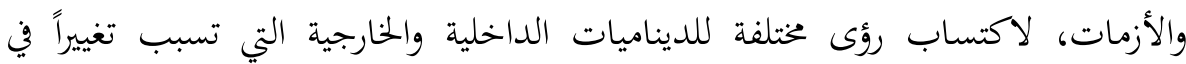
بيئها، والذي يعطي ابتحاه أكثر فعالية لمنظماتم،، وهذه الرؤى موجهة نحو المستقبل وأن

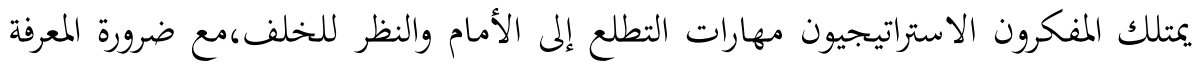
الجيدة بالوضع الحالي للمنظمة" ( Davies, 2003). ويستدل مما سبق إلى ضرورة يقظة المفكر الاستراتيجي لرؤية جميع التغيرات والتحديات

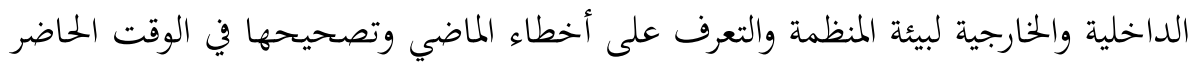
واستباق التوجه المستقبلي. أولاً: مفهوم القيادة الجحامعية: وهي العلاقات التي تربط بين فرد وبجموعة من الأفراد،

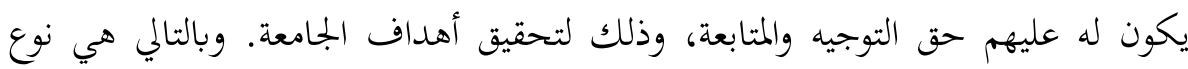
خاص من القيادة، وهي مزيج من الأسلوب الإداري والأسلوب الأكاديمي في القيادة، ووفقاً لمستوى توفر صفات القائد الجامعي بقدر قدرة القائد على التفكير الاستراتيجي، ومن صفات القائد الجامعي أن يكون: نشيطاً علمياً، وعالماً في تخصصه، الثقة في أخلاقياته، لديه ثقة في مرؤوسيه، ناجح في علاقاته الوظيفية والاجتماعية، يجيد الحديث والإنصات مع الأخرين (جوهر، 2007: ص ص 116-118)، كذلك ذكر ( الشخيبي، 2012: ص ص 108-109) بعض من الصفات الأخرى لقادة التعليم الجامعي وهي: 
أ- امتلاك رؤية لتطوير العمل الجامعي والقدرة على توصيل الرسالة للأخرين. ب-الالتزام بإتمام التخطيط الاستراتيجي في وقته.

ج- القدرة على التجديد في الجامعة، وتسهيل عمليات التحسين المستمر. د- القدرة على تطوير آليات مناسبة لمراقبة النجاح وتقويمه.

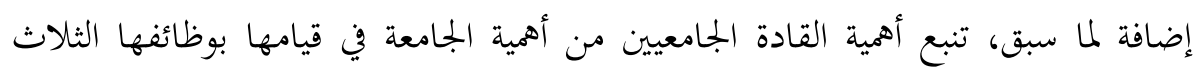

$$
\text { الآتية(الشخيبي، 2012: ص صلم2-33) }
$$

أ- العمل على إعداد القوى البشرية المؤهلة أكاديمياً ومهنياً وثقافياً في التخصصات المختلفة، لتحقيق أهداف المجتمع، ومتطلبات سوق العمل من الوظائف المهنية المتخصصة الدقيقة.

ب-البحث العلمي بهدف تقديم حلول لمشكلات المواطن والمجتمع وتطوير المعرفة الانسانية وتحقيق التنمية في كافة المجالات.

ج- خدمة المجتمع وتنمية البيئة من خلال غرس القيم والأخلاق ونشر المعرفة والثقافة والنهوض بأفراد المجتمع وتقديم المعرفة.

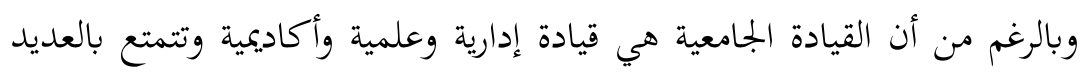
من الصفات التي تميزها إلا أها تتطلب التفكير الاستراتيجي ذو الرؤية والتوجه الاستراتيجي، فمن خلال التفكير الاستراتيجي تكون القيادة قادرة على إحداث أعمال وتصميمات ونماذج مختلفة عن الواقع الراهن وليست تقليدية والوصول إلى نتائج مختلفة تماماً وهذه هي القيادة الجامعية التي تجيد التفكير الاستراتيجي. ثانياً: خصائص القيادة الجامعية ذات التفكير الاستراتيجي:

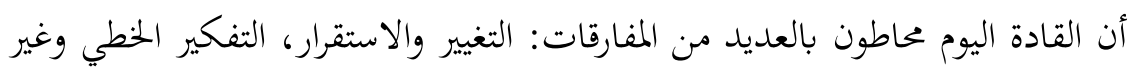

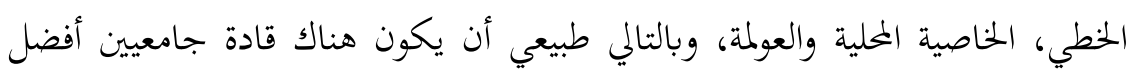
من الآخرين في الفهم والتفسير وذلك يهيئ العقلية الاستراتيجية لفهم التعقيدات التي ولي ولئي تواجه المنظمة وتطبيق فرص التغيير ، ووضع (بسابيا Pisapia) إطاراً جديداً للقيادة، 
عدد خاص بالأوراق العلمية المقدمة للمؤتم الدولي الثاني للتعليم في ليبيا، مصراتة، ليبيا. مارس 2019

حيث تطلب واقع ما بعد الحداثة من القادة أن يتفهموا سياقهم الاستراتيجي والتمتع بالثقة والكفاءة والمرونة من أجل التكيف مع منظماتمم، بالإضافة إلى تميز القائد بالمهارات والقدرات التالية(Pisapia, 2005: p.42): أ- القدرة على التأثير على الآخرين من واقع الأهمية الوظيفية والمنزلة الاجتماعية. ب-القدرة المفاهيمية التي لا غنى عنها في إدراك الترابط وأنماط العلاقات الإنسانية. ج- القدرة على اتخاذ القرارات الاستراتيجية التي تتطلب قوى التحليل والحدس.

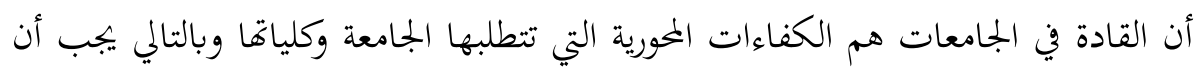
تتوافر فيهم خصائص التفكير الاستراتيجي(هاشم، 2008، ص ): أ- القدرة على تكوين الرؤى وصياغة الأهداف الاستراتيجية.

ب-الدقة والبصيرة النافذة في تقييم الأمور المستقبلية، الطلاقة الفكرية والمرونة التلقائية. ج- مهارة استشعار البيئة الخارجية بما توفره من فرص أو ما تفرضه من معوقات. د- المهارة في توفير البيانات والمعلومات وتصنيفها وتحليلها وتفسيرها.

هـ - القدرة على التجاوب أو التغاعل الاجتماعي مع الظروف والمتغيرات البيئية. و - القدرة على اتخاذ القرارات الاستراتيجية ورغبة في مواكبة الفكر الاداري المعاصر.

الخطوة الثانية: بعض النماذج والنطبيقات الأجنبية للتفكير الاستراتيجي: حيث سيتناول هذا المحور دراسة وصفية لبعض النماذج الأجنبية للتفكير الاستراتيجي وكذلك التطبيقات الأجنبية للتفكير الاستراتيجي وذلك كالآتي: أولاً: بعض النماذج الأجنبية: وهذه النماذج تنسب إلى مؤلفيها على النحو الآتي: 1. نموذج ليدكا للتفكير الاستراتيجي ( The Liedtka Model of Elements of

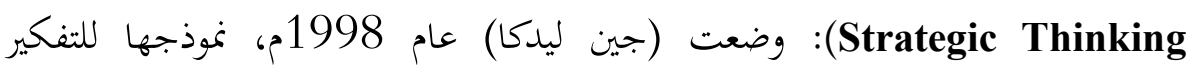

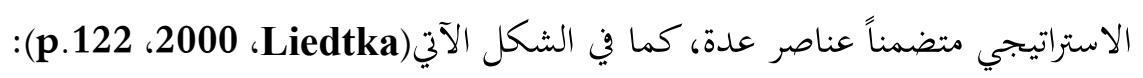


مقتح لتنمية التفكير الاستراتيجي لدى القادة بالجمامعات الليبية

مجلة كلية الآداب- العدد خاص (2) الجلد (1)

عدد خاص بالأوراق العلمية المقدمة للمؤتم الدولي الثاني للتعليم في ليبيا، مصراتة، ليبيا. مارس 2019

شكل رقم(1) عناصر التفكير الاستراتيجي وفقاً لنموذج ليدكا.

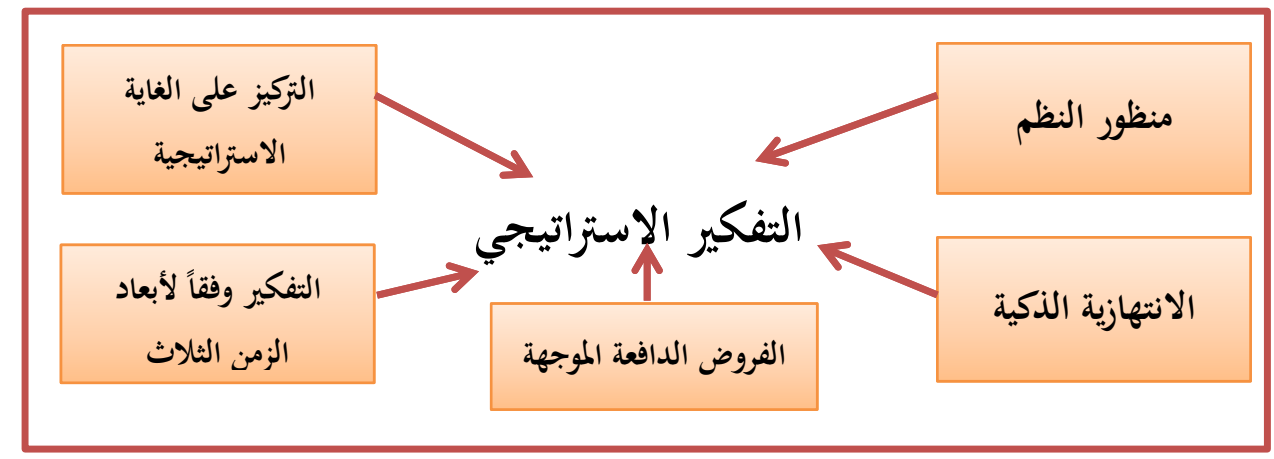

Liedtka, Jeanne M., (2000): Strategic Thinking : Can

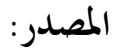
it be taught?, long range planning, Elseviar Science Ltd, Vol(31), No(1), p.125.

ويتضح من الشكل السابق أن نموذج ليدكا للتفكير الاستراتيجي يتكون من خمس عناصر

وهي كما يلي(Campbell, 2011, pp. 22-23):

أ- منظور النظم System Prospective: فالتفكير الاستراتيجي مبنى على منظور النظم، فالمفكر الاستراتيجي يمتلك نموذجاً عقلياً كنظام متكامل لتكوين القيم في إطار علاقات تبادلية بينهما. و قوة النماذج العقلية في التأثير على سلوكنا، وذُكر أن الرؤى والأفكار الجديدة تخفق عند وضعها موضع التنفيذ والممارسة، نظراً لتعارض الصور الذهنية الداخلية الراسخة للكيفية التي يعمل بها العالم، كما يجب أن تتضمن النماذج العقلية

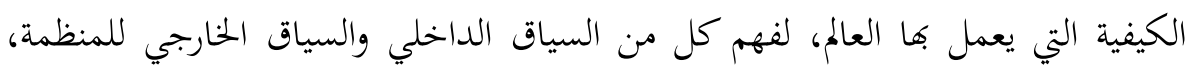

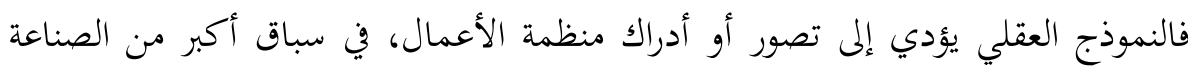

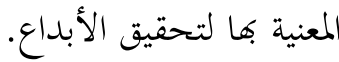

ب- التركيز على الغاية/ القصد Intent Focused: أن مصطلح الغاية الاستراتيجية يشير إلي وجهة نظر معينة عن السوق على المدى الطويل، أو بشأن الوضع التنافسي الذي تأمل المنظمة بناءه على مدار الفترة المقبلة، وبالتالي فإنه يمثل الشعور بالاتحاه، وتكون الغاية الاستراتيجية متميزة ومختلفة وتحمل طياتما وجهة نظر تنافسية وفريدة بشأن المستقبل، كما 
عدد خاص بالأوراق العلمية المقدمة للمؤتمر الدولي الثاني للتعليم في ليبيا، مصراتة، ليبيا. مارس 2019

تحمل رسالة إلى الموظفين تعدهم باستكشاف بجالات تنافسية جديدة، وبالتالي فهي تبث

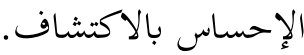

ج-الانتهاز الذكي Intelligent Opportunism: هذا العنصر يتمثل في الانفتاح على التجارب والخبرات الجديدة والتي تمكن المنظمة من الاستفادة من الاستراتيجيات البديلة والتي قد تبدو أكثر أهمية نظراً لسرعة تغيير بنية الاعمال، ويبرز هذا الأسلوب الاختلاف بين الاستراتيجية الطارئة والاستراتيجية المقصودة، وعند ممارسة المنظمة للذكاء الانتهازي فإنها تنظر بجدية المدخلات من موظفي المستوى الأذني أو الموظفين الأكثر إبداعاً من الذين إنهاء يمكنهم الإسهام في تبنى أو تحديد الاستراتيجيات البديلة والتي ربما تكون أكثر ملائمة للبيئة. د- التفكير وفقاً لأبعاد الزمن الثلاث Thinking in Time : أن الاستراتيجية لا يتم وضعها بالنظر إلى المستقبل فقط ولكن عن طريق معرفة الفجوة بين الواقع الحالي والغاية

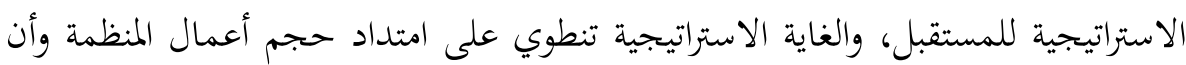
القدرات والموارد الحالية غير كافية بالدرجة التي تفرض على المنظمة أن تكون خلاقة وأكثر إبداعاً لتحقيق أقصى استفادة ممكنة من الموارد المحدودة، في حين أن النظرة التقليدية للاستراتيجية تركز على درجة التوافق بين الموارد المتاحة والفرص والغاية الاستراتيجية تؤدي

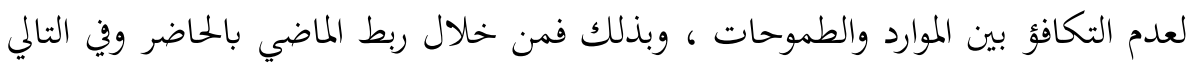
يتم ربطه بالمستقيل، فإن التفكير الاستراتيجي هو دائماً التفكير في أبعاد الزمن الثلاث. وفي فاية نموذج التفكير الاستراتيجي أوضحت ( ليدكا) أن العناصر الخمسة معاً تصف التفكير الاستراتيجي والمفكر الاستراتيجي بالنظرة الشمولية الواسعة، لرؤية جميع العلاقات التي تربط بين الأجزاء عبر المستويات الرأسية الأربعة للاستراتيجية والعناصر الأفقية من البداية حتى هاية نظام القيم، وأوضحت ليدكا في نموذجها للتفكير الاستراتيجي 
مقترح لتنمية التفكير الاستراتيجي لدى القادة بالجامعات الليبية

مجلة كلية الآداب- العدد خاص (2) الجلد (1)

عدد خاص بالأوراق العلمية المقدمة للمؤتمر الدولي الثاني للتعليم في ليبيا، مصراتة، ليبيا. مارس 2019

أن المفكر الاستراتيجي بظل منفتحاً ومتحيناً للفرص السانحة لتحديد الغاية الاستراتيجية ومحاولة تحقيقها والتأكد من مدى ملائمة الغاية الاستراتيجية.

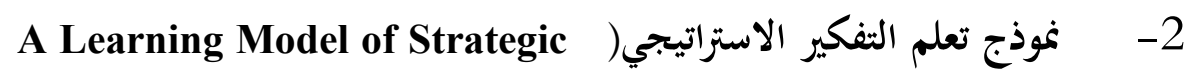
Thinking): وضع كل من ( كاسي وجولدمان Casey \& Goldman ) نموذجاً تعليمياً لتنمية قدرة الفرد على التفكير الاستراتيجي بالارتكاز على أدبيات الإدارة الاستراتيجية ويتكون النموذج من العناصر الموضحة بالشكل التالي:

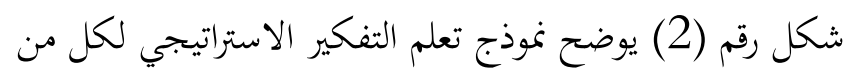

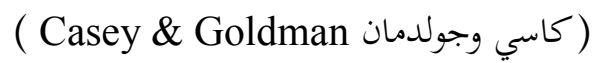

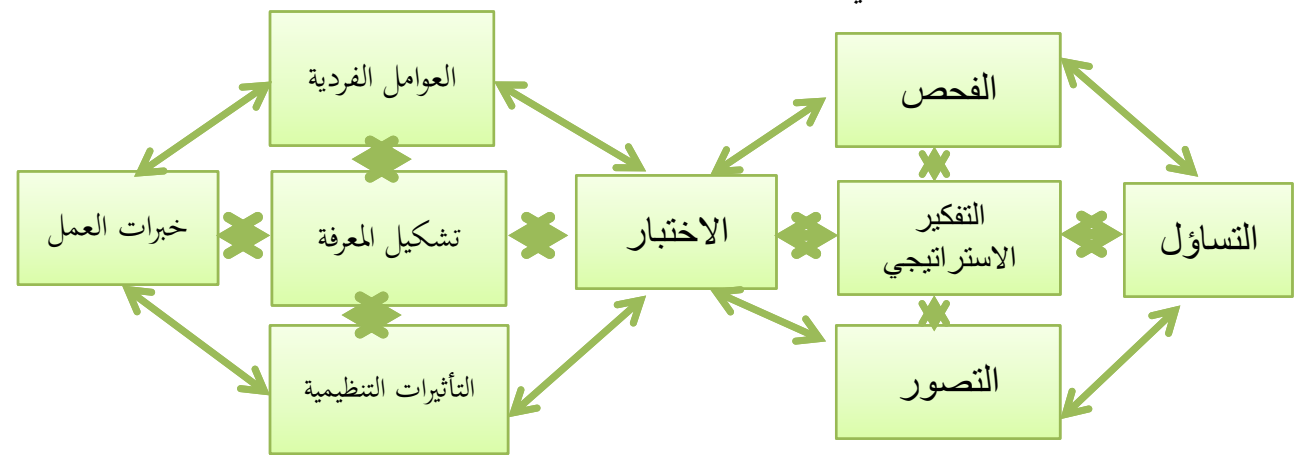

Goldman, E. \& Casy, A., (2010): Building a Culture that المصدر: Encourages Strategic Thinking, Journal of Leadership \& Organizational Studies, No(7), p124. يوضح الشكل السابق عناصر نموذج تعلم التفكير الاستراتيجي وهي كالآي:

1. خ خبرات وبحارب العمل Work Experiences : وهي تعد بمثابة المحفزات الرئيسية

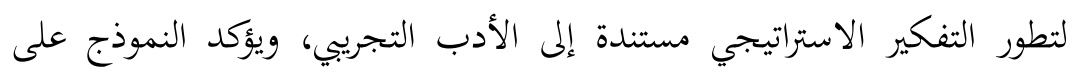

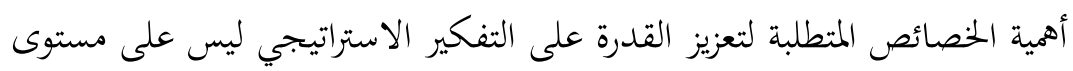

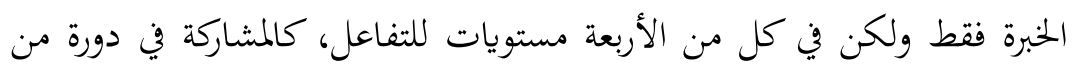
دروات التخطيط الاستراتيجي للمنظمة. 
2. تشكيل المعرفة Knowledge creation : تنتج خبرات العمل بعض أو كل أنواع المعارف الأربع اللازمة للتفكير الاستراتيجي وهي المعرفة الواقعية والإجرائية والمفاهيمية والذاتية وكذلك تشكل هذه المعارف خبرات العمل في المستقبل.

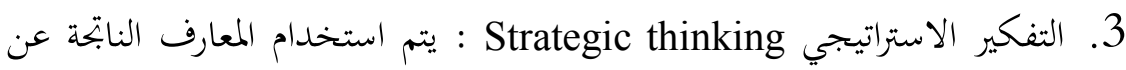
الخبرات لتحسين تطبيق الأنشطة المتضمنة في التفكير الاستراتيجي، المتمثلة في الفحص والتساؤل ووضع التصور والاختبار، والتي بدورها تخلق معارف إضافية. 4. العوامل الفردية Individual Factors : تحدد هذه العوامل يتضمن هذا النموذج نمطاً لتعلم الفرد والذي يعتبر عامل أساسي يؤثر في إنشاء المعرفة والتفكير الاستراتيجي والذي بدوره يؤثر في خبرات العمل، وتتحدد هذه العوامل الفردية في

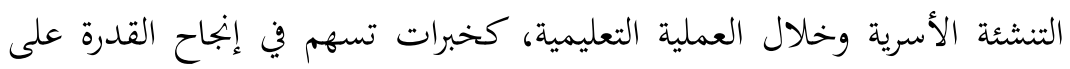

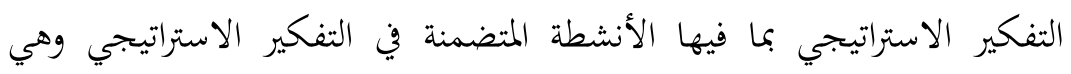
الفحص والتساؤل والتصور والاختبار والتي تتسق مع العناصر الأساسية لنظرية التعلم التجريبي لـ(كولب)، وفي ضوء هذا النموذج يمكن تفسير الفروق الفردية في التعلم من خلال الخيارات المختلفة لنمط التعلم. 5. المؤثرات التنظيمية Organizational Influencers: وتتضح هذه المؤثرات في المستويات المختلفة للمنظمة بداية من مستوى جماعة العمل والذي يعزز التنوع في كل من السن والجنس والتعليم والخبرة والحياة والمعرفة وإبداع فريق العمل

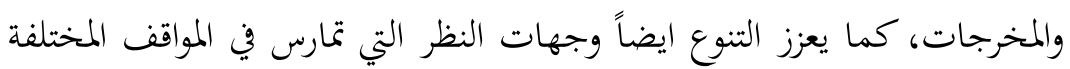
وتوسيع شبكات الحصول على المعلومات بالإضافة إلى استفادة فرق العمل من التنوع عند مشاركتها في السلطة، حيث يؤدي ذلك إلى خلق المعرفة وتنوع الفريق يمكن أن يدعم خبرات العمل والتي ربما تمثل مطلباً للآخرين.

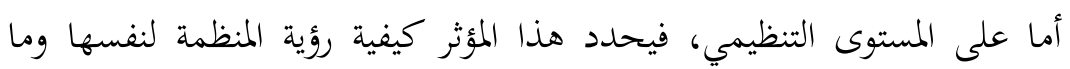

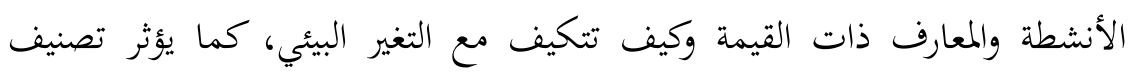


عدد خاص بالأوراق العلمية المقدمة للمؤتر الدولي الثاني للتعليم في ليبيا، مصراتة، ليبيا. مارس 2019

أنشطة التفكير الاستراتيجي على مشاركة المنظمة في خلق المعرفة وكذلك على مجموعة من خبرات العمل التي تتوفر للأفراد. أما ثقافة المنظمة فيكون لما تأثير فيما يتعلق بالاستراتيجية التنظيمية عن المعتقدات حول كفاءة المنظمة والرؤية والأهداف والمنافسة، والتحدي الذي يواجه القادة هو التقليل من الأثر السلبي للثقافة على الاستراتيجية أو إدخال شكل مختلف لتشجيع التفكير الاستراتيجي لاستراتيجية تسهم في تطوير الأفراد على المستويات التنظيمية.

وأخيراً يعكس هذا النموذج ل (كولب Kolb)، تطوير القدرة على التفكير الاستراتيجي باعتباره عملية دينامية وتفاعلية ومتكررة للتعلم من الخبرة، وبالتالي فإن كلاً من ممارسة أنشطة التفكير الاستراتيجي( الفحص، التساؤل، التصور، الاختبار)، وتطوير القدرة على القيام بذلك يحمل نفس الخصائص في التطوير غير الخطي

والمستمر (Goldman, E. , Casy, A., 2010: pp121-124). ويمكن أن نستنتج من النموذج السابق لتعلم التفكير الاستراتيجي ما يلي: أ. يُمكن القادة في الجامعات من مساعدة الآخرين على فهم العادات الخاصة بكم، والممارسات التي تتعلق بتطوير القدرة على التفكير الاستراتيجي. ب- يُكن للقادة تضمين خبرات العمل التي توضح تطور التفكير الاستراتيجي في خطط التنمية من تقاريرهم المباشرة.

ج- يمكن للقادة عند تقييم المنظمة تعظيم إمكانية القياس المقارن ودورات التخطيط الاستراتيجي خلال التأكيد على أن هذه العمليات تتضمن خصائص معينة والتي تعزز مساهتها في التفكير الاستراتيجي.

3trategic Thinking - منموذج التفكير الاستراتيجي من منظور متعدد المستويات fom a Multilevel perspective الاستراتيجي والذي يتكون من مستويين مختلفين أحدها فردي والآخر تنظيمي، وذلك 
من منطلق أن التفكير الاستراتيجي لا يحدث ببساطة في عقل واحد، ولكنه يتأثر بالسباق الاجتماعي الذي يعمل فيه الفرد، وهو يردى أنه إذا تمكنت المنظمات من تأسيس تفكير استراتيجي من هذين المستويين فإنه بمقدورها التوصل إلى الكفاءة المركزية. وهذه المستويات كالتالي Arayesh, B. \& Golmohammadi, E) 2011:

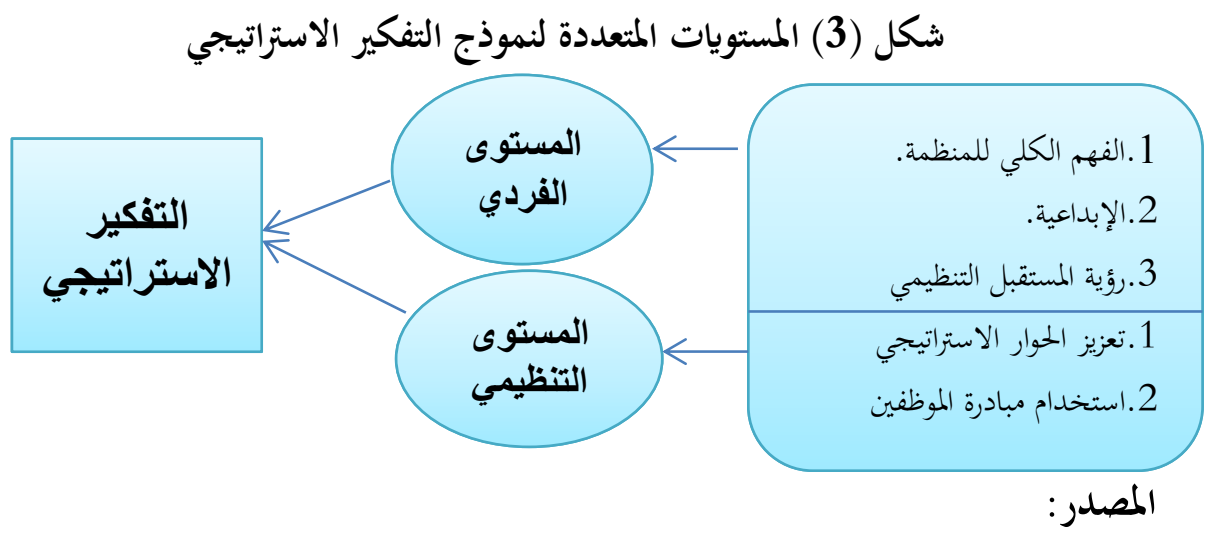

Arayesh, B. \& Golmohammadi, E. (2011): " Strategic thinking, the necessity of present managers of Iran, International Conference on financial Management and Economics, Vol(11), p. 96.

1. التفكير الاستراتيجي على المستوى الفردي: أن السلوك الفردي في المنظمات يتمثل

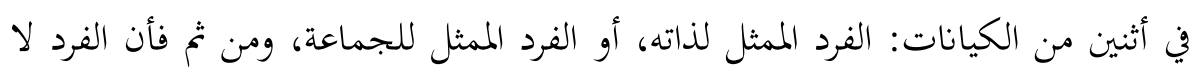
يتصرف فقط نيابة عن المنظمة في تحسين التفكير الاستراتيجي من منطلق الاحساس

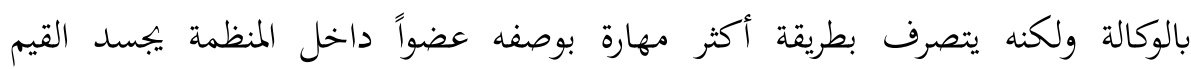
والمعتقدات والأهداف الاجتماعية وي ضوء ذلك يتضمن هذا المستوى المحاور التالية: أ- الفهم الشامل للمنظمة وبيئتها: ولتحقيق هذا الفهم يتطلب الأمر التعرف على ولى ولى

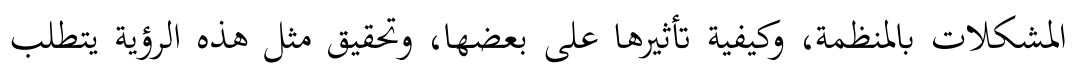
الفهم العام للأنظمة الفرعية داخل المنظمات التي تعمل في إطار النظم الكبيرة. 
عدد خاص بالأوراق العلمية المقدمة للمؤتمر الدولي الثاني للتعليم في ليبيا، مصراتة، ليبيا. مارس 2019

ب-الإبداع: وهو عملية خلاقة تبدأ مع إنتاج الفكرة الجديدة ولكي يبنى المفكر الاستراتيجي الميزة التنافسية داخل منظمته ينبغي أن يبحث عن رؤى جديدة.

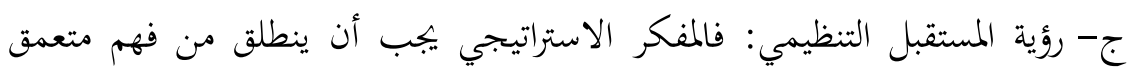

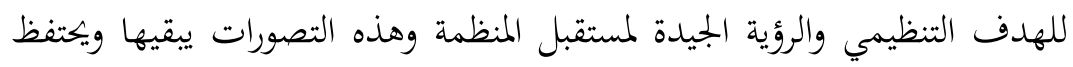
بها الأفراد في قلوبكم وعقولم ويمكن أن تسبب إدراك الحركة والقهم داخل المنظمة إلى جانب التزود بالتركيز والتأكيد على الأنشطة الميدانية داخل المنظمة. 2. التفكير الاستراتيجي على المستوى التنظيمي: حيث يؤسس التفكير الاستراتيجي خلفية في المنظمة من مجموع الفكر الاستراتيجي الفردي وكذلك تحتاج المنظمات لإنشاء الهياكل التنظيمية والعمليات والنظم التي تكون قادرة على تعزيز الحوار الاستراتيجي بين الفرق الكبيرة، وينقسم هذا المستوى إلي التالي: أ. الحوار الاستراتيجي: حيث يتطلب التفكير الاستراتيجي الوقت والتأمل لاستكشاف الأفكار ولا تستخدم مثل تلك التقليدية والسلبية في الحوارات الاستراتيجية التي تعد مصدراً هاماً للتفكير الاستراتيجي وتأسيس الرؤية التي تحتاجها المنظمات وهذا هو الإطار القانوني للمديرين الذين يشاركون في هذا المجال مع القضايا الاستراتيجية.

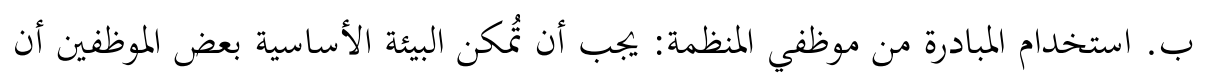
يساهموا ويطوروا الأفكار الجديدة والاستراتيجيات والتي يمكن تلخيصها فيما يلي: (1) جذب القوى الخلاقة والمبتكرة في المنظمة. (2) توفير الوقت الكافي والتسهيلات للمبادرات البحثية والمالية. (3) الحرية الكافية للقيام بالأنشطة الإبداعية وبذل المجهود. (4) استخدام نتائج الأنشطة الإبداعية ومنح المكافآت المناسبة للأفراد المبدعين. ويمكن الاستفادة من النماذج السابقة للتفكير الاستراتيجي من خلال ما يلي: 
1. ضرورة تملك قادة التعليم الجامعي لنموذج عقلي يتميز بحساسيته الشديدة للرؤى والأفكار الجديدة وكيفية إحداث التوازن بين تحقيق هذه الرؤى وطرق العمل التقليدية المألوفة. 2. ضرورة أن يتحلى القائد كمفكر استراتيجي بنظرة ثاقبة للأمور بحيث يرى النظام الجامعي ككل بنظرة شمولية وكنسق نظمي يتكون من عدة أنظمة كالأنشطة الطلابية والمناهج الدراسية وتقويم الطلاب ويتم وضع رؤية استراتيجية لتحقيق الميزة التنافسية فالمستقبل. 3. مراعاة القائد للترابط الزمني بين الماضي والحاضر لتشكيل المستقبل.

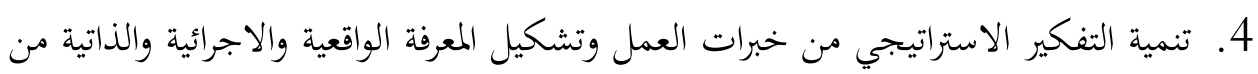
أجل تطبيق أنشطة التفكير الاستراتيجي.

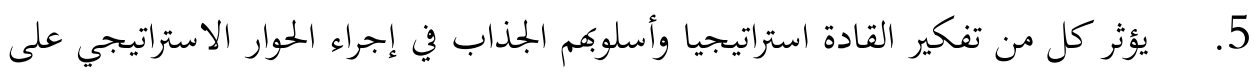
المستوى الفردي وعلى مدى استجابة العاملين ومبادرقم لتنفيذ الاستراتيجية بفعالية. المحور الثاني : بعض النطبيقات الأجنبية في تنمية التفكير الاستراتيجي:

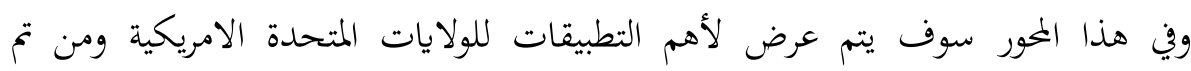

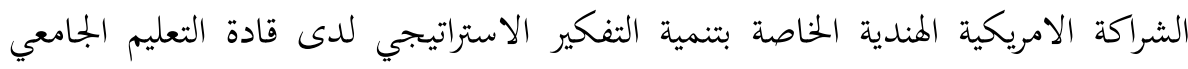
وأعضاء هيئة التدريس، وهذه التطبيقات هي (Arayesh, B. \& Golmohammadi, E. :2011. Pp111-113) أولاً: التطبيقات الامريكية: تمثلت أولى هذه التطبيقات في مركز للدراسات المهنية المستمرة بكلية المعلمين في جامعة كولومبيا (Teachers College - Columbia University)، حيث يقدم المركز العديد من البرامج التدريبية وورش العمل التي تتراوح قترتا الزمنية من يوم إلى يومين، ولا يتجاوز عدد المتدربين فيها عن خمسة عشر متدرب، وهناك برامج تدريبية عديدة حول التفكير الاستراتيجي ومنها البرنامج التدريبي حول تحفيز العقليات الاستراتيجية

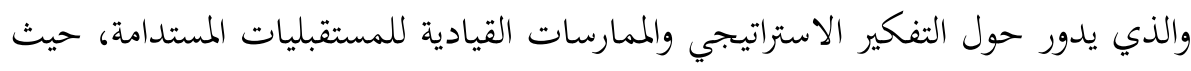
يزود هذا البرنامج المشتركين بالآليات والممارسات التي تمكنهم من تنفيذ التفكير 


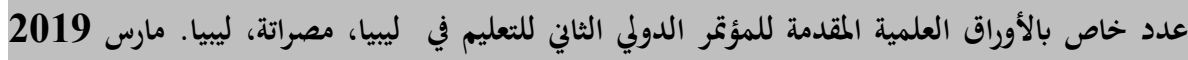

الاستراتيجي بفعالية في التعلم التنظيمي واستحداث حلول ابتكارية لاستنباط الميزة التنافسية

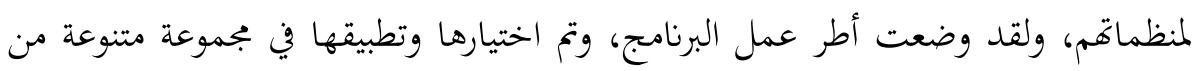

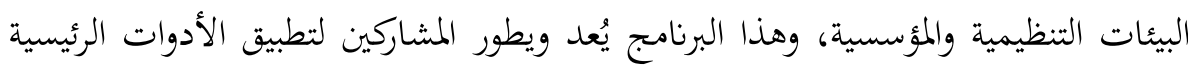
للتعلم التنظيمي والممارسات لاستباط الرؤى الاستراتيجية وتحديد أكثر العملاء أهمية في سلسلة قيمة العملاء وتعزيز المواءمة لقيادة التغيير الاستراتيجي.

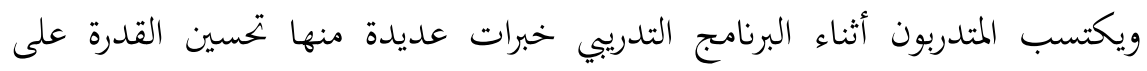
استخدام أدوات التفكير الاستراتيجي، كما يتمكن المتدرب من بناء أسلوب لقيادة

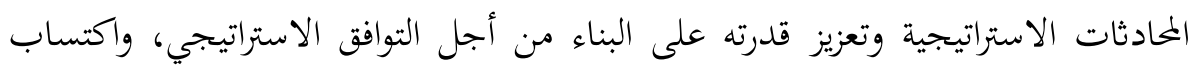
مهارات العقلية الاستراتيجية على تقييم ثقافة الابتكار الاستراتيجي لمنظمة المتدرب.

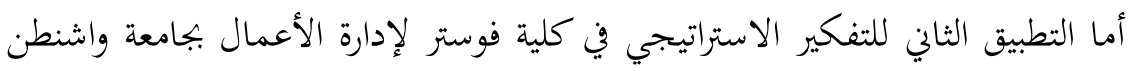
في مركز القيادة والتفكير الاستراتيجي والذي تأسس عام 2009، ليركز على التكامل بين صرامة التفكير الاستراتيجي وأهميته في كيفية تطور القيادة، ومن القواعد الأساسية للمركز هو أن يتم التركيز على بجالات القيادة والتفكير الاستراتيجي والتسريع ن الارتقاء بكلية فوستر لتكون قمة الكليات الجامعية في الاهتمام بالقيادة والتفكير الاستراتيجي في الجامعات في الولايات المتحدة الامريكية والعالم، وللمركز العديد من النشاطات والبرامج التدريبية التي تسعى لتنمية وتطوير التفكير الاستراتيجي لدى القادة وخاصة في الجامعات. ثانياً: تطبيقات التفكير الاستراتيجي من خلال الشراكة الأمريكية الهندية: والتي تمثلت

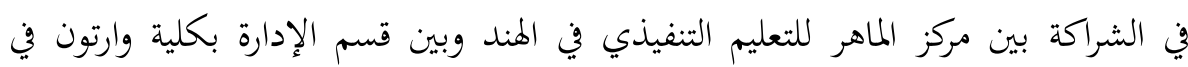
جامعة بنسلفانيا في أمريكا، حيث تم تأسيس هذا القسم عام 1881، 18 ليقرئ ليقدما معاً برامج ذات حودة عالية للقادة الجامعيين والمجتمعات المحلية والعالمية في إطار الشراكات ويتعاون مركز الماهر مع كليات إدارة الأعمال العالمية وأعضاء التدريس الناجحين في تقديم برامج تستهدف نو المواهب القيادية في الهند، ومع الخبرة السابقة في مجال التعليم التنفيذي عالمياً، يستحضر فريق المدربين الرؤى والأفكار الغنية للشركات والمتدربين. 
ويمكن التركيز في هذا الجانب على البرنامج التدريبي الخاص بالتفكير الاستراتيجي والقيادة للنمو، حيث يبدأ النمو مع صياغة الاستراتيجية وتحديد الفرص سواء كانت تحالفات أو مشروعات داخلية بالمنظمة، ومن تم وضع خطة استراتيجية لتحقيقها، على أن أن تكون هذه الخطة أيضاً مدعمة ومدفوعة من قبل قيادة فعالة، فجودة القيادة تحرك

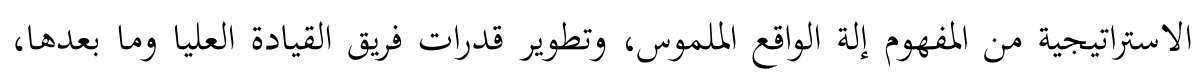
والسيطرة على التغيير مع ضرورة اتخاذ اليقظة حول التدابير المضادة من جانب المنافسين.

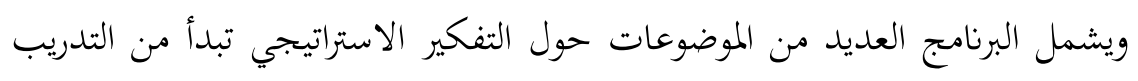
على صياغة الاستراتيجية ووضع خطط الأعمال ، وكيفية تحديد ميزة تنافسية ومحاولة

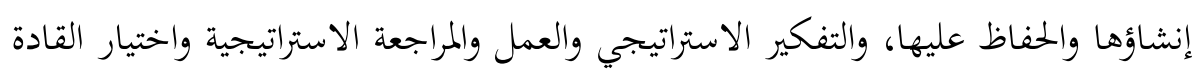

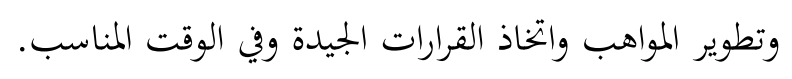
ويتضح من عرض هذا التطبيق مدى اهتمام الهند على إعداد قادها الجامعيين والقوى البشرية الماهرة لصناعة المستقبل من خلال الشراكة بين مركز الماهر للتعليم التنفيذي وكلية وارتون بجامعة بنسلفانيا، وتحرص دولة الهند على إنشاء مؤسسات التعليم العالي المتنوعة

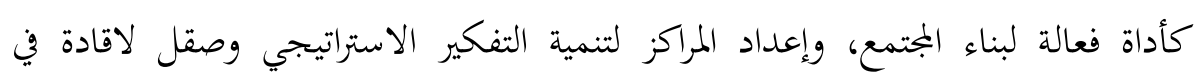
لاتلعيم لاعالي من أجل تبني استراتيجيات محددة للدولة وتحسين الجودة بها. ويتضح من خلال التطبيقات السابقة للتفكير الاستراتيجي تنوع مصادر تنميته داخل تئل

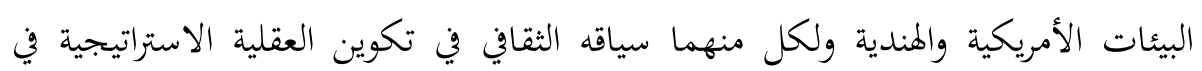
منظمات التعليم الجامعي أو مؤسسات الأعمال التجارية، كما أن هناك أوجه تشابه بين

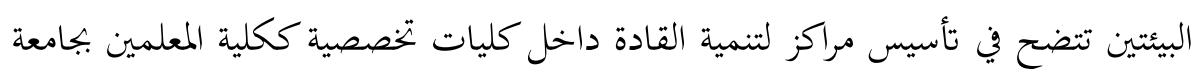
ولومبيا وكلية إدارة الأعمال بجامعة واشنطن في أمريكا وكذلك مشاركة قسم الإدارة بكلية وارتون في جامعة بنسلفانيا بأمريكا مع مركز الماهر للتعليم التنفيذي بالهند. 


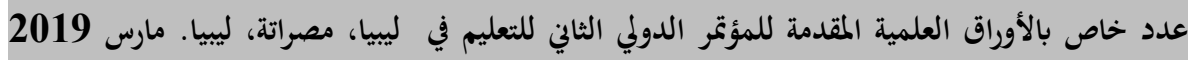

\section{الخطوة الثالثة: النموذج المقترح لتنمية التفكير الاستراتيجي لدى القادة بالجامعات}

\section{الليبية في ضوء بعض النماذج والنطبيقات الأجنبية:}

في ضوء ما تقدم من عرض للبنية النظرية للتفكير الاستراتيجي وقادة التعليم الجامعي، وكذلك البنية الفكرية لبعض النماذج والتطبيقات الأجنبية للتفكير الاستراتيجي، فأن البحث الحالي توصل إلى أن تنمية التفكير الاستراتيجي لقادة التعليم الجامعي في ليبيا يقوم على مرتكزات أساسية وهي: 1. التفكير النظمي: حيث يتطلب التفكير الاستراتيجي ضرورة تفرد كل قائد بنموذج عقلي للفهم الشامل لكل الأجزاء الداخلية والخارجية للمؤسسة الجامعية وكيفية تكيفها مع التغير البيئي، ومن أجل إحداث القادة للتغيير المنشود بالجامعة لابد من إجراء

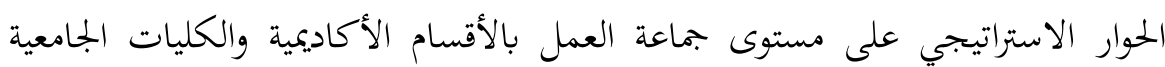
لتأسيس الرؤية المستقبلية التي تحتاجها الجامعة مع ضرورة استخدام المبادرة لجذب القبام القوى الخلاقة والمبدعة من أعضاء هيئة التدريس والإداريين.

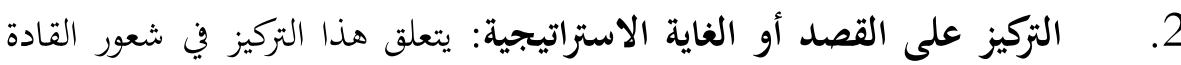
بالاتجاه الاستراتيجي نحو تحقيق غاية متميزة ومختلفة للجامعة بمساعدة وإدراك جميع العاملين لاستكشاف مجالات تنافسية جديدة كبرنامج دراسي متميز وإرساء قواعد الديمقراطية مع المحافظة على حماية حرية الانسان وحقوقه وبتطلب ذلك الاستفادة من خبرات العمل السابقة في كيفية تحديد الرؤية الاستراتيجية للمنظمة الجامعية، والإفادة من لمن الفروق الفردية للقادة وأعضاء هيئة التدريس عند تشكيل فرق العمل اللازمة لصياغة

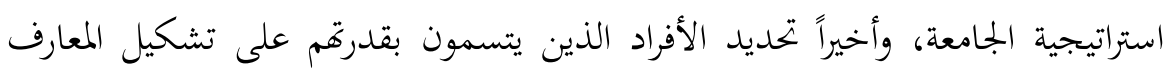
الذاتية لما لمذه المعارف من تأثيرات فعالة عند تكوين الغابة الاستراتيجية المتميزة. 3. الانتهاز الذكي للفرص: حيث يؤدي تفعيل هذا العنصر داخل الجامعة للتواصل

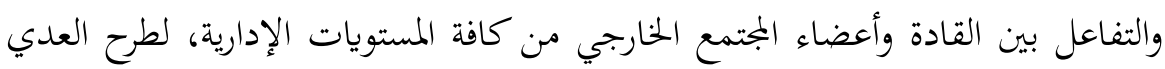


من الأفكار والاحتمالات المتدرجة للخيال من أجل انتهاز الفرص التي تحقق للتعليم

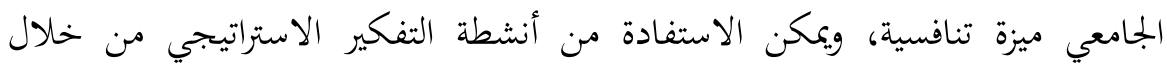
تكوين فرق للعمل لدراسة البيئات الجامعية المتنوعة بالدول المتتدمة والدول التي حققت قدراً من التقدم للتعرف على كيفية صياغتها لاستراتيجيات مبتكرة على ضوء ظروفها الثقافية وبالتالي توفير الدافعية للعاملين بإمكانية تفاعلهم ومشاركتهم لانتهاز الفرصة الذكية للارتقاء بمستوى الجامعة.

4. التفكير وفقاً لأبعاد الزمن الثلاث: التفكير الاستراتيجي بساعد قادة الجامعات

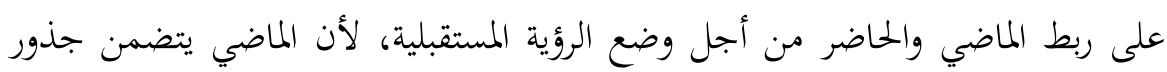
الوضع المراد تغييره، ثم التحكم في معطيات الحاضر وتوجيهـا نحو التوجه المستقبلي الممثل لرؤية المؤسسة الجامعية، وهذا يتطلب ضرورة تحديد مشكلات وأزمات منظمات التعليم الجامعي بالماضي وأسباب ذلك لمعالجة تلك المشكلات عند صباغة الاستراتيجية المستقبلية ودراسة العوامل الثقافية التي تشكل الوقت الحاضر للمجتمع وكيفية التحكم في هذا الحاضر عند وضع الرؤية الاستراتيجية لمنظمة التعليم الجامعي. ولتسهيل تنفيذ النموذج المقترح لتنمية التفكير الأستراتيجي لدى قادة التعليم الجامعي في ليبيا يتطلب هذا النموذج ضرورة توفير آليات محددة لتحقيق النتائج المرجوة منه، وهذه الآليات كما يلي: 1- تأسيس مراكز لتنمية القادة في الجامعات الليبية: بحيث أصبح من الضرورة تأسيس مراكز داخل كل جامعة في ليبيا لتنمية قدرات ومهارات القادة في الجامعات الليبية وبصورة دورية ومستمرة ومواكبة لكل التطورات الحاصلة في مجال القيادة والإدارة، وأن يكون لهذا المركز هيكل تنظيمي وميزانية منفصلة وتوفير كافة الامكانيات والدعم لكي ودموني يحقق أهدفه المرجوة، وخاصة في مجال التفكير الاستراتيجي لقادة الجامعات والذي 
بدوره سيؤدي بالجامعات الليبية لتحقيق الميزة التنافسية أمام نظيراها سواء على

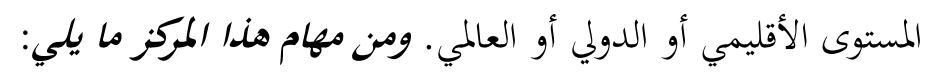
أ- تنظيم وإعداد دورات تدريبية وورش عمل لكافة أعضاء هيئة التدريس لتأهيلهم

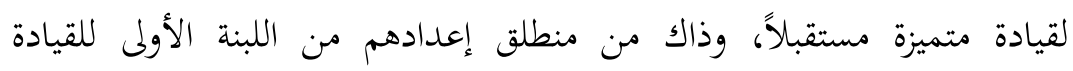

$$
\text { المستقبلية ومشاركتهم فالتخطيط الاستراتيجي والأهداف الاستراتيجية. }
$$

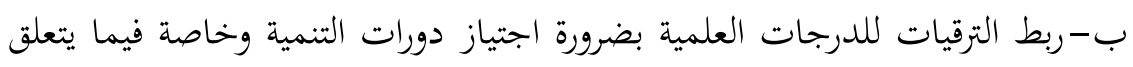
بالتفكير الاستراتيجي، وأن يكون اجتياز هذه الدورات أحد المعايير الأكاديمية

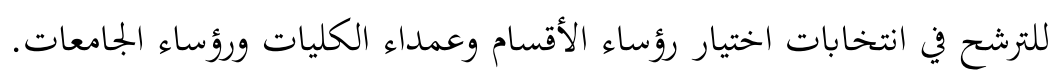
ج-تنوع الموضوعات التدريبة وورش العمل لاحتواء كافة جوانب تطوير العمل الجامعي مثل دورات التفكير الاستراتيجي لمعايير الجودة في العملية التدريسية بالأقسام، القيادة الاستراتيجية والتفكير الاستراتيجي، التفكير ومهارات الحوار

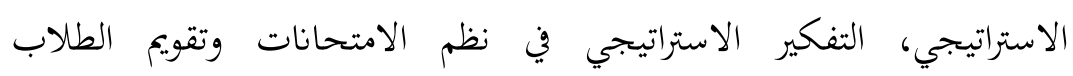
بالكليات، أنشطة التفكير الاستراتيجي والفاعلية التعليمية. 2- عقد شراكات بين الجامعات الليبية والجامعات العالمية لتنمية قدرات القادة الجامعيين: حيث تتمثل هذه الآلية في إقامة العديد من الشراكات بين الجامعات الليبية ومكاتب التدريب بها مع نظيراتا بالجامعات العالمية لاكساب القادة المهارات والقدرات التالية:

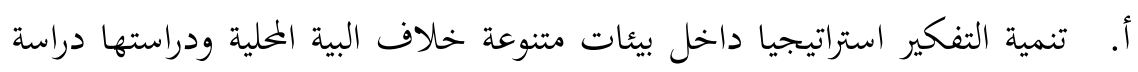
منظومية من أجل انتهاز الفرص الذكية وتحقيق الميزة التنافسية.

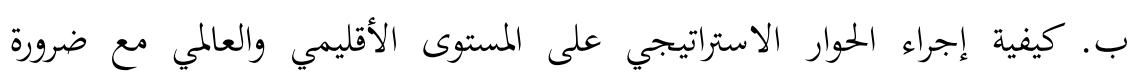

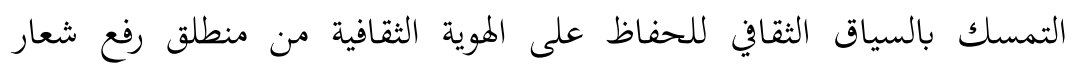

$$
\text { (الجامعات الليبية والرؤى المستقبلية). }
$$

إن هذا النموذج المقترح لن يواجه أي معوقات عند تنفيذه إذ أخذت المرتكزات والأليات

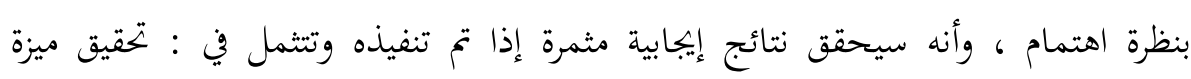


مقتح لتنمية التفكير الاستراتيجي لدى القادة بالجامعات الليبية

مجلة كلية الآداب- العدد خاص (2) الجلد (1)

عدد خاص بالأوراق العلمية المقدمة للمؤتم الدولي الثاني للتعليم في ليبيا، مصراتة، ليبيا. مارس 2019

تنافسية للجامعة، ومواكبة اقتصاد الجامعة، وفعالية أنشطة التفكير الاستراتيجي، وإرضاء جميع المستفيدين من خدمات الجامعات الليبية، وقبول التغيير الإيجابي وعدم مقاومته لأنه

$$
\text { هو الثابت الوحيد في العالم. }
$$

شكل (4) يوضح النموذج المقترح لتنمية التفكير الاستراتيجي لدى قادة الجامعات الليبية وما يتضمنه من مرتكزات وآليات لسهولة تنفيذه

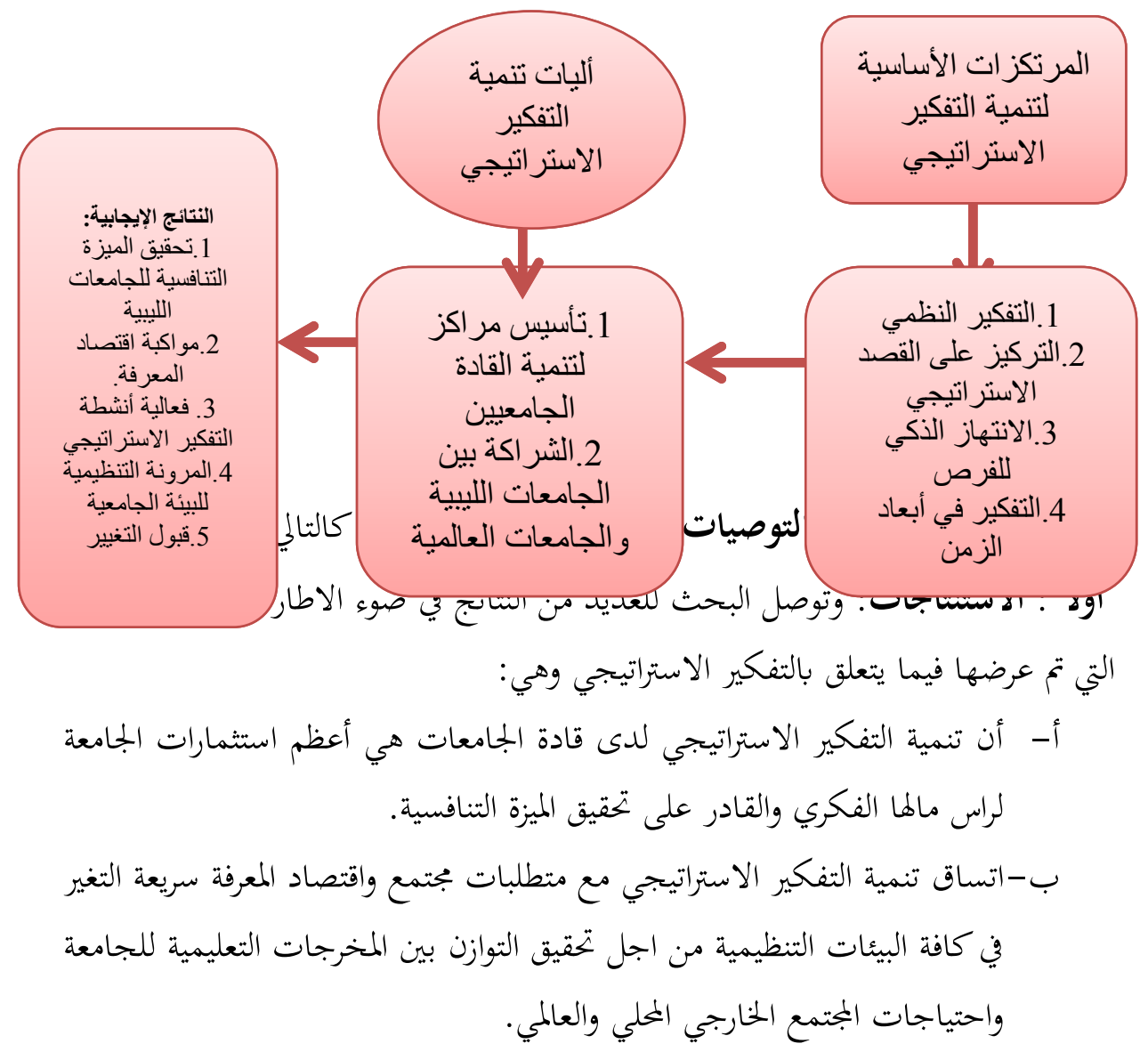


ج-أن نشر ثقافة التفكير الاستراتيجي داخل البيئات الجامعية بداية من رؤساء

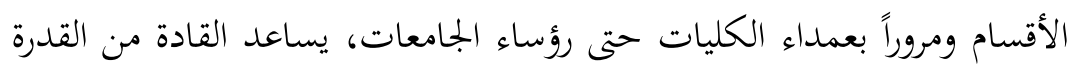
على الابتكار في تنفيذ أنشطة الخطة الاستراتيجية وتدبير مواردها المالية. د- أن التفكير الاستراتيجي هو القادر على تصور مستقبلي مختلف عن الحاضر ووضع استراتيجيات خيالية ومبتكرة من شأها تمكين الجامعة من تلبية رغبات جميع المستفيدين كالطلاب وأعضاء التدريس لتحقيق الميزة التنافسية. هـ- تنبع أهمية التفكير الاستراتيجي لقادة التعليم في الجامعات من أهمية الوظائف المنوطة بهم والتي تلزم القادة بصفات التفكير الاستراتيجي كالقدرة على الإصغاء الاستراتيجي والمحادثات الاستراتيجية للمشتركين في صياغة الاستراتيجية والقدرة على وضع رؤية وأهداف لتطوير العمل الجامعي والقدرة على تكوين فرق العمل المتعاونة والفعالة لوضع الاستراتيجية.

و - ضرورة تحلي القادة بالمزيد من المعارف واكتساب الخبرات المتنوعة بالجامعة وتطوير لمائه

عادات الفهم والتخطيط العقلاني وترتيب التحديات وفقاً لأولوية مواجهتها. ز- التوصل إلى النموذج المقترح لتنمية التفكير الاستراتيجي لفادة الجامعات الليبية والذي سيساهم في تحقيق الميزة التنافسية للجامعات الليبية من خلال الرؤية المستقبلية الواضحة والشاملة.

$$
\text { ثانياً : التوصيات : وهي: }
$$

1. إنشاء مراكز تدريبية لتنمية التفكير الاستراتيجي لدى قادة الجامعات الليبية بداية

$$
\text { من رؤساء الاقسام وعمداء الكليات ورؤساء الجامعات. }
$$

2. ربط الترقيات للدرجات العلمية بضرورة اجتياز دورات التنمية وخاصة فيما يتعلق بالتفكير الاستراتيجي، وأن يكون اجتياز هذه الدورات أحد المعايير الأكاديمية للترشح في انتخابات اختيار رؤساء الأقسام وعمداء الكليات ورؤساء الجامعات. 
3. تفعيل مكاتب التدريب الموجودة داخل الجامعات مع ضرورة الاستفادة من الخبراء

$$
\begin{aligned}
& \text { في الجامعات الليبية لأقامة هذه الدورات التدريبية والبرامج التنموية. } \\
& \text { ثالثاً: المقترحات: وفي ضوء البحث الحالي يقترح التالي: }
\end{aligned}
$$

1. إجراء بحث حول نظام تدربيي مقترح لتنمية التفكير الاستراتيجي لدى القادة في لئي

$$
\text { الجامعات الليبية. }
$$

2. إجراء بحث حول تنمية التفكير الاستراتيجي لدى مدراء مدارس التعليم في مدينة

$$
\text { درنة . }
$$

3. بحث مقترح حول متطلبات تنمية التفكير الاستراتيجي لدى القادة بالمؤسسات

$$
\text { التعليمية في ليبيا "دراسة تحليلية". }
$$

\section{قائمة المراجع}

$$
\text { أولا: المراجع العربية: }
$$

جوهر، صلاح الدين.(2007). اختيار القيادات الجامعية. المؤتمر السنوي الخامس عثر تأهيل

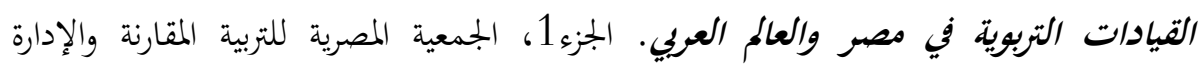
التعليمية، القاهرة، دار الفكر العربي. الرقيعي، كريمة المبروك.(2016). نظام تدربيي مقترح لمديري وحدات الجودة بالجامعات الليبية في ضوء أدوراهم المستقبلية. (رسالة دكتوراه غير منشورة)، قسم التربية المقارنة والإدارة التعليمية، كلية التربية ، جامعة عين شمس، القاهرة. الشخبي، علي السيد.(2012). آفاق جلديدة في التعليم الجامعي العبي. القاهرة: دار الفكر العربي.

$$
\text { الشخيبي، علي السيد.(2012). المرجع سابق. }
$$

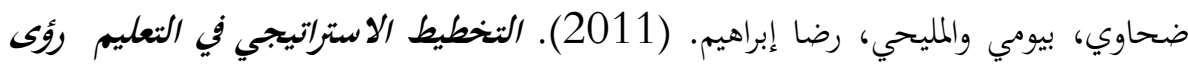
مستقبلية ونماذج تطبيقية. القاهرة، دار الفكر العربي. 
عليان، ربحي مصطفى و غنيم، عثمان محمد(2000). مناهج وأساليب البحث العلمي، النظرية والتطبيق. عمان، دار صفاء للنشر والتوزيع.

المركز الوطني لضمان جودة واعتماد المؤسسات التعليمية والتدريبية.(2010). تثرير عن زيارات استطلاعية لبعض مؤسسات التعليم العالي. ليبيا ،طرابلس.

المنظمة الليبية للسياسات والاستراتيجات. (2017). واقع التعليم العالي في ليبيا 2016. طرابلس ، النوفليين.

هاشم، فهلة عبدالقادر. (2008). تطوير أداء الجامعات المصرية في ضوء إدارة الجودة الاستراتيجية، مجلة التربية، السنة 11، العدد 23، القاهرة، الجمعية المصرية للتربية المقارنة والإدارة التعليمية.

يونس، طارق شريف. (2006). الفكر الاستراتيجي للقادة، المنظمة العربية الإدارية للتنمية، القاهرة.

$$
\text { ثانيا: المراجع الأنجليزية: إن }
$$

Arayesh, B. \& Golmohammadi, E. (2011): " Strategic thinking, the necessity of present managers of Iran, International Conference on financial Management and Economics, Vol(11), p. 96.

Arayesh, B. \& Golmohammadi, E. (2011). Opc.

Campbell D., and others. (2011). Business Strategy- An Introduction, 3td ED, U.K, palgrave macmillan.

Davies, B,. (2003). Rethinking Strategy and Strategic Leadership in School. Educational Management AdminstrationdLeadership. Vol(31). N(3).

Davies, B,. (2003). Rethinking Strategy and Strategic Leadership in School. Educational Management AdminstrationdLeadership. $\operatorname{Vol}(31)$. N(3).

Robinson,J. (2012). A Comparative, Holistic, Case Study of the Implementation of thr Strategic Thinking Protovole and Traditional Strategic Planning Processes at a Southeastern University. PHD, The college of Education, Florida Atlantic University. 
Waters, E,. (2011). Understanding Strategic Thinking and Devevloping Strategic Thinking. 4th . U.S. Army war College Public Affairs Office.

Waters, E,. (2011). Opt.

Pisapia, J. and Others. (2005). Developing a strategic: Constructing the measures. Leadership Review. 5 (1).

Liedtka, Jeanne M., (2000). Strategic Thinking Can it be taught?, long range planning. Elseviar Science Ltd, $\operatorname{Vol}(31)$, No(1).

Campbell D., and others(2011): Business Strategy- An Introduction, 3rd ED, palgrave macmillan, U.K.

Goldman, E. \& Casy, A., (2010): Building a Culture that Encourages Strategic Thinking, Journal of Leadership \& Organizational Studies, No(7), p124.

Goldman, E. \& Casy, A., (2010): Building a Culture that Encourages Strategic Thinking, Journal of Leadership \& Organizational Studies, $\operatorname{No}(7)$ 